\title{
Research on the Origin of Nonmetallic Inclusions in High-Strength Low-Alloy Steel Using Automated Feature Analysis
}

\author{
Alexander A. Kazakov ${ }^{1}$, Sergei Ryaboshuk ${ }^{1}$, Daria Lyubochko ${ }^{1}$, Lev Chigintsev ${ }^{1}$ \\ ${ }^{1}$ St. Petersburg State Polytechnical University/Metallurgical Technologies Department, \\ St. Petersburg, Russian Federation
}

The aim of this paper is an investigation of thermo-temporal nature of nonmetallic inclusions, which were found in samples taken from high-strength low-alloy (HSLA) steel forgings and plates, treated with silico-calcium. For an objective assessment of the chemistry of non-metallic inclusions, a SEM-EDS microanalysis method called automated feature analysis (AFA) was used. This technique makes it possible to examine large quantities of inclusions only comparable to optical microscopy methods, but AFA provides also a compositional data along with conventional metrics [1]. By chemical composition, the inclusions in the acquired database mostly belong to the Al-Mg-Ca-S-O system. Note that the composition of these inclusions also contains small concentrations of manganese and silicon.

All inclusions are divided into four main groups (Fig.1): I) inclusions of the ternary system $\mathrm{Al}_{2} \mathrm{O}_{3}-\mathrm{MgO}-\mathrm{CaO}$, which belong to the region of coexistence of solid magnesium spinel and liquid oxide melt; II) inclusions of the same system, which belong to the region of liquid oxide melt; III) calcium aluminates of the binary system $\mathrm{Al}_{2} \mathrm{O}_{3}-\mathrm{CaO}$; and IV) $\mathrm{Al}_{2} \mathrm{O}_{3}-\mathrm{MgO}$ system compounds. It should be noted that almost all detected inclusions contain sulfur, wherein the mass of sulfides increases with increasing magnesium content in the inclusions. In the presence of magnesium, calcium has more opportunities to interact with sulfur.

Next, we consider in detail the thermo-temporal nature of the first and second group inclusions, as the most complex. Inclusions of the first group in cast metal have rounded shape and size up to $15-30 \mu \mathrm{m}$ (Fig.2a). Initially, primary and secondary solid magnesium spinel inclusions and liquid oxy-sulfides formed in the melt (Fig.2b). During crystallization of the oxy-sulphide melt $\left(\mathrm{CaO} \approx 42 \% ; \quad \mathrm{MgO} \approx 28 \% ; \mathrm{Al}_{2} \mathrm{O}_{3} \approx 23 \% ; \mathrm{SiO}_{2} \approx 6 \% ; \mathrm{S} \approx 0.12 \%\right)$, the next compounds form sequentially: first $\mathrm{MgO} \cdot \mathrm{Al}_{2} \mathrm{O}_{3}$ and $\mathrm{MgO}$, which continue to grow on the surface of spinel already existed in the steel melt, then $2 \mathrm{CaO} \cdot \mathrm{SiO}_{2}, 3 \mathrm{CaO} \cdot \mathrm{MgO} \cdot 2 \mathrm{Al}_{2} \mathrm{O}_{3}$ and finally, $\mathrm{CaS}$ (Fig.2c).

Inclusions of the second group (Fig.3a) differ from the first group with a higher content of calcium, which in some cases exceeds $45 \%$. The thermo-temporal nature of the nucleation of these inclusions is that only liquid oxy-sulphide melt $\left(\mathrm{Al}_{2} \mathrm{O}_{3} \approx 25 \% ; \mathrm{CaO} \approx 35 \% ; \mathrm{MgO} \approx 32 \%\right.$; $\mathrm{SiO} 2 \approx 7 \%$; $\mathrm{S} \approx 0.05 \%$ ) solidify until the temperature drops to $1555^{\circ} \mathrm{C}$ in the steel melt (Fig. 3b). Solid oxides like $\mathrm{CaO} \cdot \mathrm{Al}_{2} \mathrm{O}_{3}, \mathrm{CaO} \cdot 6 \mathrm{Al}_{2} \mathrm{O}_{3}$ and $\mathrm{Al}_{2} \mathrm{O}_{3}$ form sequentially at lower temperatures in molten steel and later form solid oxy-sulphides. Solidification begins with $\mathrm{MgO}$ and $\mathrm{MgO} \cdot \mathrm{Al}_{2} \mathrm{O}_{3}$ formation, particles of which have correct facets due to conditions of free growth in liquid steel (Fig. 3c). Upon further cooling, calcium silicates, $\mathrm{CaO} \cdot 3 \mathrm{MgO} \cdot 2 \mathrm{Al}_{2} \mathrm{O}_{3}$ and finally $\mathrm{CaS}$ form.

Thermodynamic calculations [2] of nonmetallic inclusion formation in the liquid and solidifying steel melt, including solidification processes of forming oxy-sulfide liquid inclusions, permit explanation of the variety of phases in complex multiphase inclusions. 


\section{References:}

[1] T Taniguchi et al, ISIJ International 51 (2011) p. 1957.

[2] C Bale et al, Calphad, 26 (2002) p.189

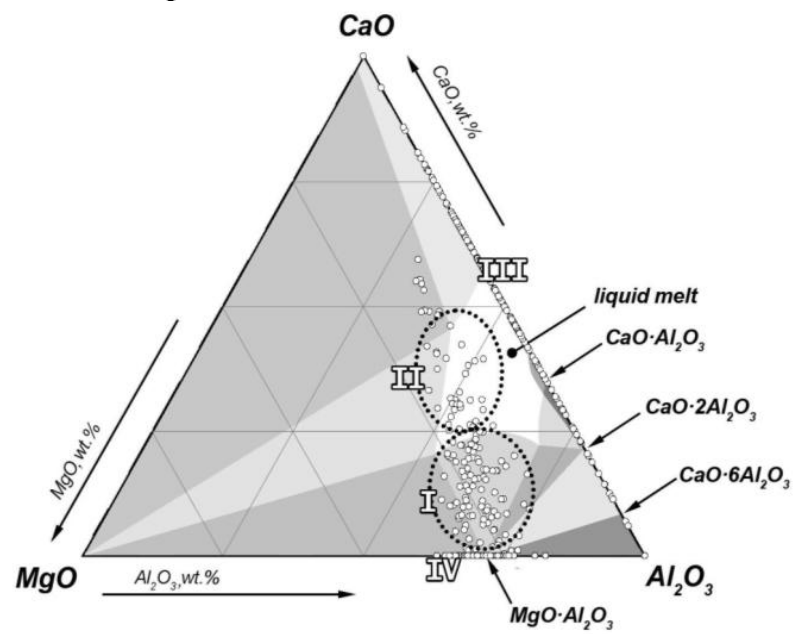

Figure 1. Chemical composition of inclusions and phase diagram of $\mathrm{Al}_{2} \mathrm{O}_{3}-\mathrm{MgO}-\mathrm{CaO}$ system at $1550^{\circ} \mathrm{C}$

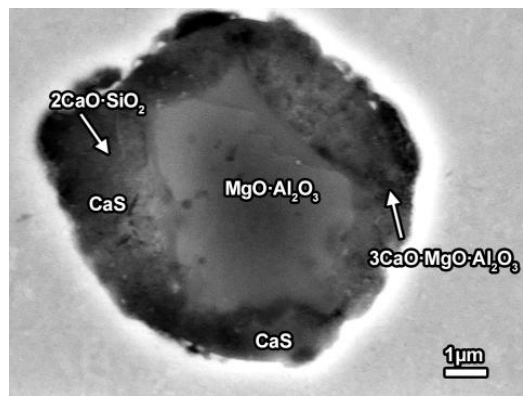

a)

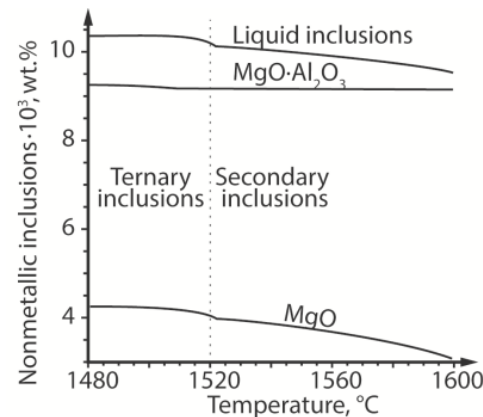

b)

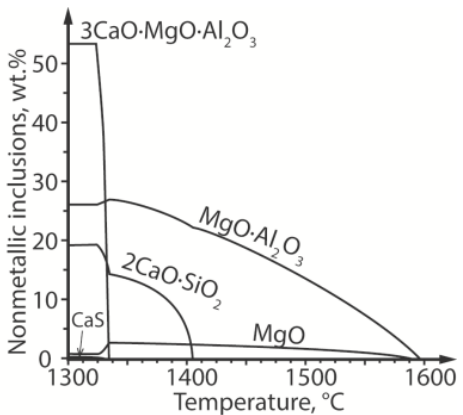

c)

Figure 2. First group: (a) distinctive inclusion and its phase composition; (b) thermodynamic modeling of phase formation during cooling and solidification of the liquid steel; (c) crystallization of liquid oxysulphide inclusions

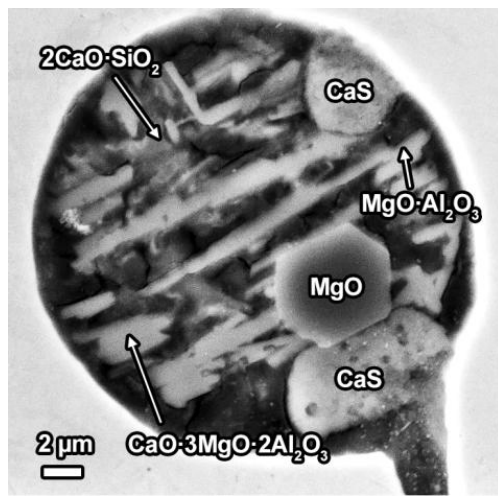

a)

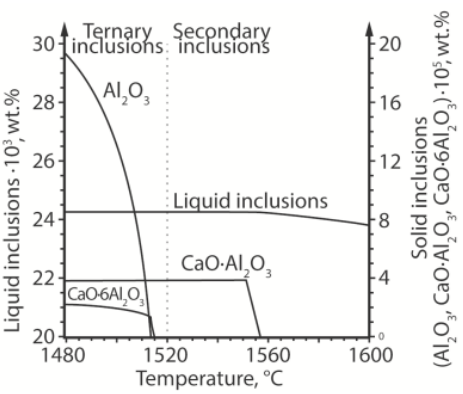

b)

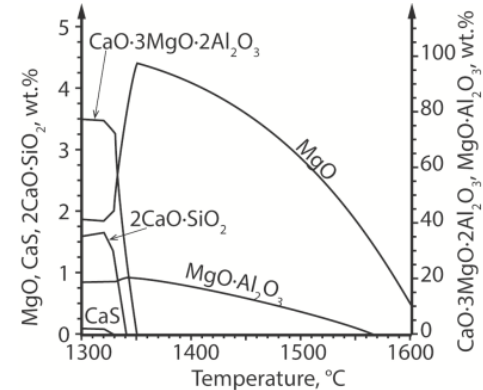

c)

Figure 3. Second group: (a) distinctive inclusion and its phase composition; (b) thermodynamic modeling of phase formation during cooling and solidification of the liquid steel;

(c) crystallization of liquid oxysulphide inclusions 